
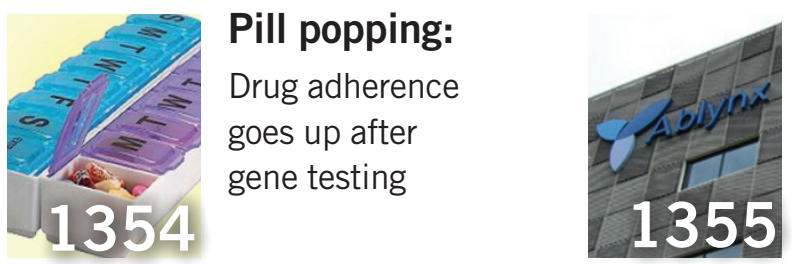

Nanobody shop:

Single-domain antibodies attract several drug companies

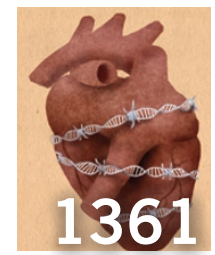

DNA autopsies:

Genetic testing of the dead proposed

to help the living

\title{
Sun sets on protein initiative, casting shadow over drug discovery
}

Celia Goulding has spent the past three years trying to crack the structure of MmpL3, a protein encoded by Mycobacterium tuberculosis that is involved in the assembly of the bacterium's cell wall. As one of the principal investigators of the Tuberculosis Structural Genomics Consortium (TBSGC), Goulding and her colleagues study proteins like MmpL3 in an effort to rationally design the next generation of therapeutics against the infectious pathogen.

Goulding's work could soon be in jeopardy. On 24 September, the US National Institute of General Medical Sciences (NIGMS) announced plans to wind down the Protein Structure Initiative (PSI), the 15-year, \$885 million program that spawned the TBSGC and supported much of Goulding's research. Crucially, the PSI has also led to the formation of four large-scale centers for high-throughput structure determination, nine centers for membrane protein structure studies, an openaccess repository called the Protein Data Bank and numerous research partnerships.

"You need big collaborations for this type of work, and now that will stop," says Goulding, a structural biologist at the University of California-Irvine.

"We'll reap the benefits of the technology developed through PSI, but we'll coast on what we've got," adds George Phillips, a biochemist at Rice University in Houston. "It won't continue to be advanced."

Come 2015, when PSI's allocated funding is scheduled to end, even pharmaceutical companies could start to feel the loss of the dedicated NIGMS program, which has occupied about $3 \%$ of the agency's budget for the past 13 years. For example, researchers at GlaxoSmithKline's Tres Cantos Medicines Development Campus in Spain, with an eye to new tuberculosis treatments, are now investigating compounds that inhibit the malate synthase enzyme-the structure of which was solved by James Sacchettini and other members of the TBSGC with the help of PSI-funded highthroughput centers (Chem. Biol. 19, 1556-1567, 2012).

"There's much more impetus for pharma to develop these kind of drugs if we can provide them with the protein structures they need," says Sacchettini, director for the Center for Structural Biology at Texas A\&M University in College Station. "This will be a big setback because the infrastructure built into the program will disappear, and we won't be able to build that up again."

\section{A structured approach}

The PSI launched in 2000 as a three-phase effort designed to fast track the process of visualizing three-dimensional shapes of proteins to better understand how the structure of these molecules helped them function. The hope was that researchers could then synthesize small molecules that were complementary in shape and charge to the solved proteins and that these drugs would therefore interact with and bind to their desired targets.

In the first five-year phase, PSI-funded scientists developed automated processes that could shorten the time needed to make crystallized structures of proteins from about a year down to a couple of weeks. In the second phase, researchers used those more efficient methods to find the previously unknown

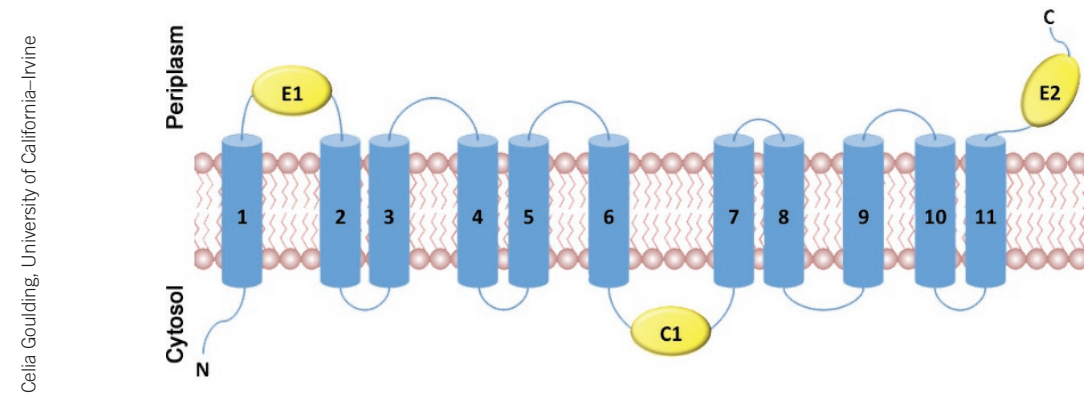

Lacking structure: The PSI could help crack the still unsolved structure of MmpL3.

structures of more than 5,000 proteins. "They developed robotics and imaging techniques that weren't possible a decade ago," says Jeremy Berg, a biochemist at the University of Pittsburgh Medical Center in Pennsylvania who led the NIGMS from 2003 to 2011. "Now you can do crystallography by FedEx.”

Despite the many advances, the PSI's first decade produced only 128 human protein structures. The third phase of the initiative, dubbed PSI:Biology, was meant to shift away from solving as many structures as possible and to bring the focus around to medically relevant proteins. These include traditionally more difficult human structures, such as those found in protein-protein complexes or receptors embedded in the cell membrane. But according to Berg, there was never a clear consensus on which proteins to prioritize.

As part of a scheduled interim assessment, an evaluation panel convened at the halfway point of PSI:Biology to determine what kind of impact the program was having. That panel presented its findings at an NIGMS advisory council meeting in September, concluding that the third phase didn't focus enough on proteins relevant to human health.

Two new committees-one of which will include staff from NIGMS and other branches of the US National Institutes of Health, the other of which will be made up of external scientists from the research community-will now decide how to dismantle PSI and what aspects of the initiative are worth salvaging. "The recommendation wasn't to eliminate all the resources created, but to cut down," explains Judith Bond, a biochemist at the University of North Carolina School of Medicine in Chapel Hill who co-chaired the evaluation committee.

"A goal of PSI:Biology was to set the stage for this transition," NIGMS director Jon Lorsch told Nature Medicine. "The fundamental question is, "What is the most effective and efficient way to invest the taxpayers' money to promote the fundamental biomedical research that enables all future medical and technological breakthroughs?"' Answers should come next year after the two new committees present their findings.

Elizabeth Devitt 